\title{
MMC-Based PV Single-Phase System with Distributed MPPT
}

\author{
Simone Barcellona, Marzio Barresi and Luigi Piegari *(D) \\ Department of Electronics, Information and Bioengineering, Politecnico di Milano, 20133 Milano MI, Italy; \\ simone.barcellona@polimi.it (S.B.); marzio.barresi@polimi.it (M.B.) \\ * Correspondence: luigi.piegari@polimi.it
}

Received: 26 June 2020; Accepted: 27 July 2020; Published: 1 August 2020

\begin{abstract}
The presence and evolution of static power converters in electric grids are growing on a daily basis. Starting from the most used voltage source converter (VSC), passing through the use of multilevel converters, the most recent configuration is the so-called modular multilevel converter $(\mathrm{MMC})$. Because of its intrinsic advantages, it is used not only in high-voltage systems but also in lowand medium-voltage ones to interface renewable energy sources such as photovoltaic (PV) panels. Several configurations and maximum power point tracker (MPPT) algorithms have been proposed and analyzed for MMC-PV-based systems. However, when using distributed MPPTs, partial shading conditions cause a problem. The PV panel can be directly connected to the MMC using its dc link or submodule. Based on this configuration, this paper proposes a novel control strategy that tracks both the ac grid current and ac circulating current for a single-phase low-voltage system to obtain the maximum power under any irradiance condition. The effectiveness of the proposed control strategy is demonstrated through time-domain simulation results.
\end{abstract}

Keywords: modular multilevel converter; PV panel; MPPT; distributed MPPT

\section{Introduction}

Static power converters are one of the most interesting and promising technologies still under evolution. Their uses are manifold, and their presence in electric networks is growing. In fact, they can be used as electrical drives, active filters, interfaces for joining different electric grids, connection devices for energy storage devices, such as batteries and supercapacitors, and renewable energy sources, such as photovoltaic (PV) panels and wind turbines. The latter are spreading in the entire electric network (high-, medium-, and low-voltage systems). Moreover, they are used to form the well-known micro-grids, which can work either in the island mode or grid-connected mode simply through the use of power converters.

One of the most employed power converters is the voltage source converter (VSC). It is typically composed of insulated-gain-bipolar-transistors (IGBTs), through which two different grids (ac/dc) can be connected to each other. Two- or three-level VSCs are usually employed for low- and medium-voltage systems. On the other hand, in high-voltage systems, because of the limited maximum rated voltage of IGBTs, the use of a traditional multilevel VSC becomes complicated. To overcome this issue, one solution is to use more IGBTs in series to reconstruct the single switches composing the VSC. However, this makes the device more complex and much more expensive with respect to the intrinsic advantages of such a configuration. In recent years, modular multilevel converters (MMCs) represent a novel technology able to overcome the issues related to a high-voltage system while simultaneously presenting other intrinsic advantages. MMCs present a reduced harmonic content, modularity, and more control degrees of freedom. Although MMCs are suitable for high-voltage systems, their other intrinsic advantages can make them suitable for other applications in both medium- 
and low-voltage systems. In particular, PV panels are usually interfaced with the electric network through voltage source inverters (VSIs) and dc/dc boost converters [1]. The latter are usually employed to extract the maximum power using one of the maximum power point tracking (MPPT) algorithms. In most cases, numerous PV cells are connected in series and parallel to each other to form the PV modules. Several modules can be connected in series to form a string. Different strings can then be connected in parallel to form an array. In the centralized MPPT (CMPPT) configuration, the whole array is usually connected to the ac grid through a single VSI with or without a dc/dc converter and/or a galvanic transformer [2-4]. Although this kind of configuration is quite simple, it has a large power loss in the case of partial shading. Indeed, the MPPs of PV modules have different voltage and current values when differently radiated. For this reason, it is not possible, with a single tracker, to make each PV panel work at its MPP [5,6]. In general, the different panels in one PV string could lead to the presence of more than one local maximum in the power-voltage characteristic curve of the equivalent series PV module. This could be a problem for the CMPPT algorithm [7]. In [8-14], the authors assessed several strategies to find the global maximum power point of that curve. In [15], the authors proposed to change the electrical connections of the PV panels to maximize the configuration under shading conditions. The main drawback of this method is the need for several switches. Another strategy to solve this issue is the use of a distributed MPPT (DMPPT). In the literature, it is possible to find several kinds of DMPPTs. Nevertheless, two main families can be recognized. The first one is the DMPPT at the string level, in which each string of the array is controlled separately to allow each of them to reach its own maximum power point. It is possible to use as many VSIs as strings or only one centralized VSI and a dc/dc converter for each PV string $[16,17]$. The problem of the partial shading of modules of the same string is still present, and the presence of bypass diodes brings to zero the power produced by the shaded modules. The second family is the DMPPT at the module level. In this way, each PV module is separately controlled by the acting MPPT for each module. This family includes module-integrated parallel inverters (also called PV micro-inverters) [18], module-integrated parallel converters [19,20], module-integrated series converters [21,22], and module-integrated differential power processors [23]. In this way, under any shading condition, each PV module can extract its maximum power. On the other hand, the high number of converters (VSI and or dc/dc converters) yields a very expensive solution.

In recent years, the use of the MMC for PV interfacing has started to be analyzed. The authors in [24] used the MMC to interface PV panels with the grid. In this case, the PV panels were connected to the dc side of the MMC, not allowing the implementation of a DMPPT. A very interesting improvement was made in $[25,26]$, where the authors connected each PV module to each submodule (SM) of the MMC through a boost converter. This method was similar to the one proposed in [18] with several micro-VSIs, and it can be considered to be a DMPPT at the module level solution. However, the high number of boost converters prevents this solution from being optimal. Instead, in [27], a novel and interesting idea was to connect each PV module directly to the capacitor of each SM of the MMC. Therefore, the system is much less expensive but more difficult to control. In fact, in order to extract the maximum power from each PV module, in the case of partial shading, each voltage of each SM capacitor should be controlled at the MPP of the related PV module. This solution presents all the advantages of the structure in which each PV panel is controlled separately, as in [18], with neither the problem of the multi-local power points of the PV strings nor the high number of other converters. Furthermore, all the advantages of the MMC can be used instead of the classical VSI. Nevertheless, in the solution proposed in [27], tests were performed using an MMC structure with only two levels per arm. Moreover, they used one supplemental redundancy module per arm to adjust the dc voltage in the case of shading. Finally, their control strategy fixed the dc voltage of the MMC to a given reference value. In every case, the structure of the converters could be designed for a general number of phases. Although the three-phase structure is the most common, even single-phase and multi-phase structures (with more than three) are used. Focusing on the MMCs, while the three-phase and multi-phase 
configurations do not need a real dc link, the single-phase MMC, in order to provide the current return path, needs a real dc link with the middle-point accessible [28,29].

In the present work, a structure similar to the one proposed in [27] was proposed and tested, using different simulations. The main contribution of the present work is a method to control the MMC to avoid the use of redundancy modules and directly generate the dc voltage reference using the MPPT algorithm of each PV module. Moreover, the dc voltage reference is not kept constant but depends on the shading conditions. Of course, the dc voltage value is in a working range suitable for producing the required ac voltage. Therefore, the PV panels have to be opportunely sized based on both the number of MMC levels and grid characteristics.

Although most of the connections are performed through three-phase systems, nevertheless, in low-voltage electric networks, even single-phase appliances can be of interest. Moreover, this study can be used as the basis for a future extension in three-phase systems. For this reason, in this work, an MMC structure was investigated for a low-voltage single-phase system with a rated power of $6 \mathrm{~kW}$. This meant that, unlike the structure proposed in [27], in which a three-phase MMC was employed, here a single-phase MMC composed of only two arms and a real dc link with the central point accessible was used.

\section{Converter Topology}

Figure 1 shows the circuit configuration of the proposed single-phase MMC. It is composed of two arms, referred to as the upper and lower arms, whose mid-point is connected to the grid voltage through its resistance $R_{g}$ and inductance $L_{g}$. Each arm of the MMC is composed of a series arrangement of SMs whose switching is coordinated to generate a quasi-sinusoidal output voltage. Moreover, a single coupled arm inductor is used in order to obtain a weight reduction and less influence on the output voltage. Finally, the dc side of the MMC is composed of the two capacitors, $C_{d c}$, needed to create the central point for the neutral connection of the grid.

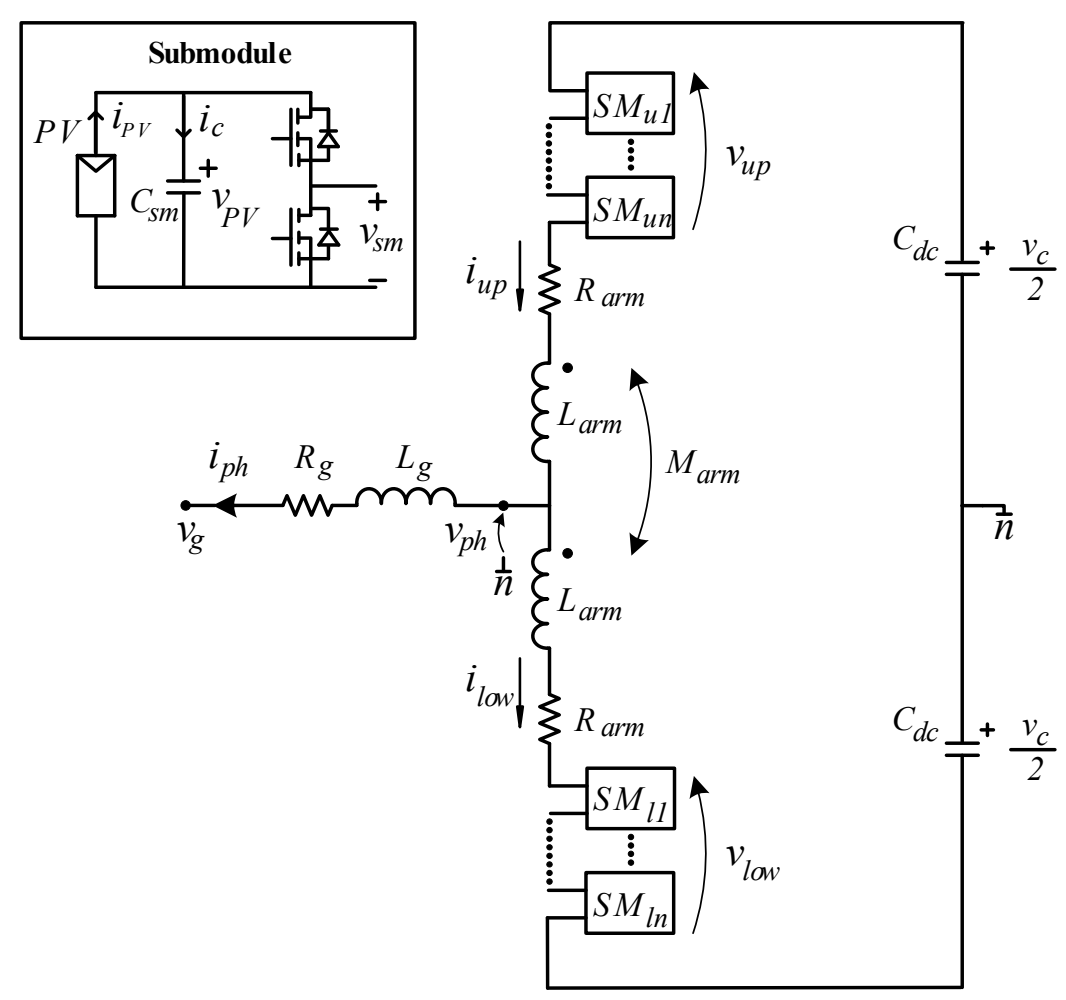

Figure 1. Topology of single-phase modular multilevel converter (MMC) with PV modules embedded in each submodule. 
Considering Figure 1, according to Kirchoff's voltage law, the following expressions can be derived:

$$
\left\{\begin{array}{l}
v_{p h}=\frac{v_{c}}{2}-v_{u p}-R_{a r m} i_{u p}-L_{a r m} \frac{d i_{u p}}{d t}-M_{a r m} \frac{d i_{\text {low }}}{d t} \\
v_{p h}=-\frac{v_{c}}{2}+v_{\text {low }}+R_{\text {arm }} i_{\text {low }}+L_{\text {arm }} \frac{d i_{\text {low }}}{d t}+M_{\text {arm }} \frac{d i_{\text {up }}}{d t}
\end{array}\right.
$$

where $v_{p h}$ is the output phase voltage of the MMC; $v_{u p}$ and $v_{\text {low }}$ are the voltages applied by the upper and lower arms, respectively; $v_{c}$ is the voltage of the dc bus; $R_{a r m}$ is the arm resistance; $L_{a r m}$ is the arm inductance, and $M_{a r m}$ is the mutual coupling of the arm inductances. Finally, $i_{u p}$ and $i_{\text {low }}$ are the upper and lower arm currents, respectively. Let us define grid current $i_{p h}$ and circulating current $i_{\text {circ }}$ as follows:

$$
\left\{\begin{array}{l}
i_{\text {ph }}=i_{\text {up }}-i_{\text {low }} \\
i_{\text {circ }}=\frac{i_{u p}+i_{\text {low }}}{2}
\end{array}\right.
$$

Furthermore, we can define the circulating voltage as follows:

$$
v_{\text {circ }}=v_{\text {low }}+v_{\text {up }}
$$

Therefore, according to (1) and (2), the output phase voltage can be expressed as follows:

$$
v_{p h}=\frac{v_{l o w}-v_{u p}}{2}-\frac{R_{a r m}}{2} i_{p h}-\frac{L_{a r m}}{2} \frac{d i_{p h}}{d t}+\frac{M_{a r m}}{2} \frac{d i_{p h}}{d t}
$$

and the output circulating voltage is

$$
v_{\text {circ }}=-\left(2 R_{\text {arm }} i_{\text {circ }}+2 L_{\text {arm }} \frac{d i_{\text {circ }}}{d t}+2 M_{\text {arm }} \frac{d i_{\text {circ }}}{d t}\right)+v_{c}
$$

The voltage of the dc bus is supported by the two $C_{d c}$ capacitors. Thus, it can be obtained as follows:

$$
v_{c}(t)=-\frac{2}{C_{d c}} \int_{0}^{t} i_{c i r c} d \tau+v_{c}(0)
$$

where $v_{\mathcal{c}}(0)$ is the initial voltage value of the dc bus.

Under normal working conditions, the output phase voltage contains only the fundamental ac component, while the circulating voltage has to contain a dc component as well. In fact, the MMC needs an opportune dc voltage to work correctly. The latter is the dc voltage that charges the two $C_{d c}$ capacitors to the dc voltage. This means that under a steady state condition, the dc component of the circulating voltage does not produce any dc component in the circulating current. Thus, the integral term in (5) will have a zero average value. On the other hand, during transients, the circulating current contains a dc component that charges or discharges the $C_{d c}$ capacitors.

Moreover, looking at (3), by using coupled arm inductors with a unitary coupling coefficient, the output phase voltage, $v_{p h}$, does not depend on the arm inductance but only on the difference between the voltages applied by the upper and lower arms. In light of the above, the output phase voltage (with only the ac component) is related to the powers exchanged (active and reactive) with the grid, while the ac component of the circulating voltage is related to the portioning of those powers between the two arms. In fact, in a case where the two arms had the same solar irradiances, the total power exchanged with the grid would be equally divided between the two arms themselves. Therefore, the circulating current would be nil. On the other hand, if the available powers in the two arms were different from each other, the circulating current would no longer be nil. This is a crucial aspect for our controller because to extract the maximum power from each PV module under any irradiance condition, it should provide an opportune value for the circulating current. 
The two arms are composed of a series of a certain number of SMs. Each SM is composed of a half-bridge converter connected to cell capacitor $C_{s m}$ and a PV module. Considering that the two switch states are always complementary to each other, the possible SM states are as follows:

- $\quad S M_{\text {state }}=1$

When the SM is in state 1 , whether arm current $i_{s m}$ is positive or negative, switch $T 1$ is in the conduction mode. Under the condition shown in Figure 2a, the current that flows through the capacitor, the sum of $i_{p v}$ and $i_{s m}$, charges it. If the arm current is negative and less than $i_{p v}$ in magnitude, the current that flows through the capacitor will charge it (Figure 2b). Instead, if the arm current is negative but higher than $i_{p v}$ in magnitude, the capacitor will discharge (Figure 2c).

- $S M_{\text {state }}=0$

When the SM is in state 0 , whether arm current $i_{s m}$ is positive or negative, switch $T 2$ is in the conduction mode. In both cases, only the PV current will flow through the capacitor charging it.

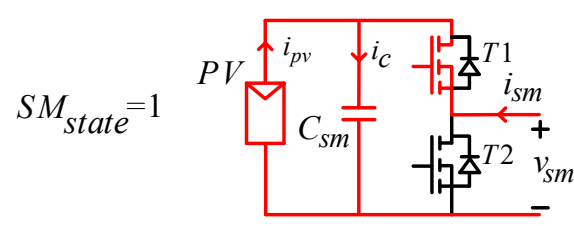

(a)

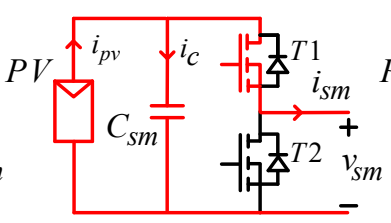

(b)

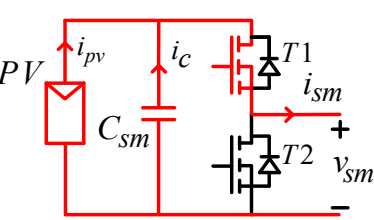

(c)

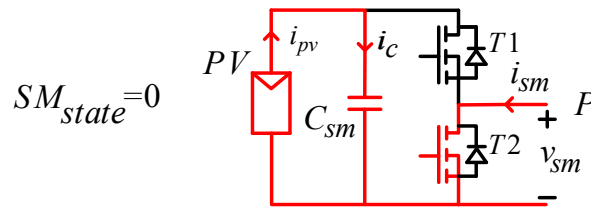

(d)

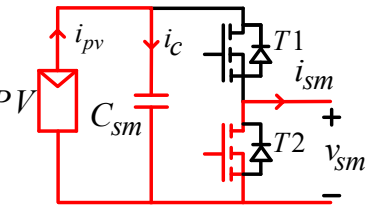

(e)

Figure 2. Possible states of submodule depending on direction of arm and PV currents: (a) SM in on-state, with positive arm current and charging capacitor; (b) SM in on-state, with negative arm current and discharging capacitor; (c) SM in off-state, with negative arm current and discharging capacitor; (d) SM in off-state, with positive arm current and charging capacitor; (e) SM in off-state, with negative arm current and charging capacitor.

\section{Converter Sizing}

The circuit parameters can be designed starting from grid voltage $v_{g}$ and the power ratings. The minimum operational dc voltage, taking into account that the converter should provide active and reactive power, is defined as follows:

$$
v_{d c \_ \text {min }}=2 k v_{g \_p e a k}
$$

where $k$ is a correction factor needed for power regulation, and $v_{g_{-} p e a k}$ is the peak of the rated grid voltage.

Then, the number of SMs is defined according to different requirements such as the total harmonic distortion, converter power losses, and power and voltage ratings of the semiconductor devices.

Moreover, the PV modules embedded in each SM of the MMC are composed of the series and parallel connections of several PV sub-modules. The number of series PV sub-modules can be derived as follows:

$$
n_{p v \_s e r i e s}=\frac{v_{d c_{\_} \text {min }}}{n_{\text {sm }} V_{\text {mppt_min }}}
$$


where $n_{s m}$ is the number of sub-modules and $V_{\text {mppt_min }}$ is the minimum optimal operative PV voltage determined at the minimum irradiance at which the system should work. In this way, the proper operation of the system at irradiances different from the maximum one is guaranteed.

Then, in order to reach the desired power rating, the number of parallel PV sub-modules is defined as follows:

$$
n_{\text {pv_parallel }}=\frac{P_{\text {rated }}}{n_{\text {arm }} n_{s m} n_{p v \_s e r i e s} P_{p v}}
$$

where $P_{\text {rated }}$ is the rated plant power, $n_{\text {arm }}$ is the number of arms (i.e., two in the single-phase MMC), and $P_{p v}$ is the rated power of a single PV sub-module.

\section{Proposed Control Strategy}

The proposed control strategy is designed in order to generate the following voltage references for the upper and lower arms:

$$
\left\{\begin{array}{l}
v_{u p}^{*}=-v_{p h}^{*}+\frac{v_{c i r c}^{*}}{2} \\
v_{\text {low }}^{*}=v_{p h}^{*}+\frac{v_{\text {circ }}^{*}}{2}
\end{array}\right.
$$

where $v_{p h}^{*}$ is the output phase voltage reference that contains only the ac component, and $v_{c i r c}^{*}$ is the circulated voltage reference defined as follows:

$$
v_{c i r c}^{*}=v_{c i r, a c}^{*}+V_{d c}^{*}
$$

As previously stated, the dc component of the circulating voltage, $V_{d c}$, is the dc voltage of the MMC, while the ac component is controlled to extract the maximum power from each arm under any irradiance conditions.

Figure 3 shows the scheme of the proposed control strategy. This can be divided into three main controllers: the MPPT control system, power management system, and modulation technique. The MPPT control system defines the optimal voltage references of all the PV modules. These reference signals, through the power management system, define the reference dc voltage, $V_{d c^{\prime}}^{*}$ and the reference voltages of the SM capacitors, i.e., the voltages of the PV modules, $V_{p v \_u p, i}$ and $V_{p v \_l o w, i}$, in order to extract the maximum power at a given solar irradiance. Therefore, this controller gives the related output phase and circulating voltage references, which according to (9), generate the output upper and lower arm voltage references. Finally, these references are synthesized through the MMC by implementing the phase disposition pulse width modulation technique (PD-PWM) [30]. Its operating principle is to compare the reference with multiple carriers placed at different levels having the same amplitude, frequency, and phase angle.

\subsection{MPPT Control System}

The MPPT control system is a crucial part of the PV system. Indeed, its aim is to define both the total dc voltage, $V_{d c}^{*}$, at which the MMC should operate and the voltages of each PV module, $V_{p v} u p, i$ and $V_{p v \_l o w}, i$ to obtain their maximum power under a given solar irradiance.

Several methods to estimate the maximum power point have been proposed in the literature, including the hill climbing, perturb and observe (P\&O), incremental conductance, fractional short circuit current, fractional open circuit voltage, fuzzy logic, neural network, and other methods reviewed in [31]. In the present study, the $\mathrm{P} \& \mathrm{O}$ method was selected because it is a more straightforward and diffused method that induces a perturbation in the operating voltage of the PV system. In particular, an adaptive $\mathrm{P} \& \mathrm{O}$ algorithm was implemented. The main difference with the traditional $\mathrm{P} \& \mathrm{O}$ algorithm was the fact that the perturbation applied was not a fixed value but changed with the $d P / d V$ ratio. Defining certain thresholds, a larger $d P / d V$ ratio led to a greater perturbation value being applied and vice versa. In this way, a good dynamic performance and stability at a steady state were ensured. 


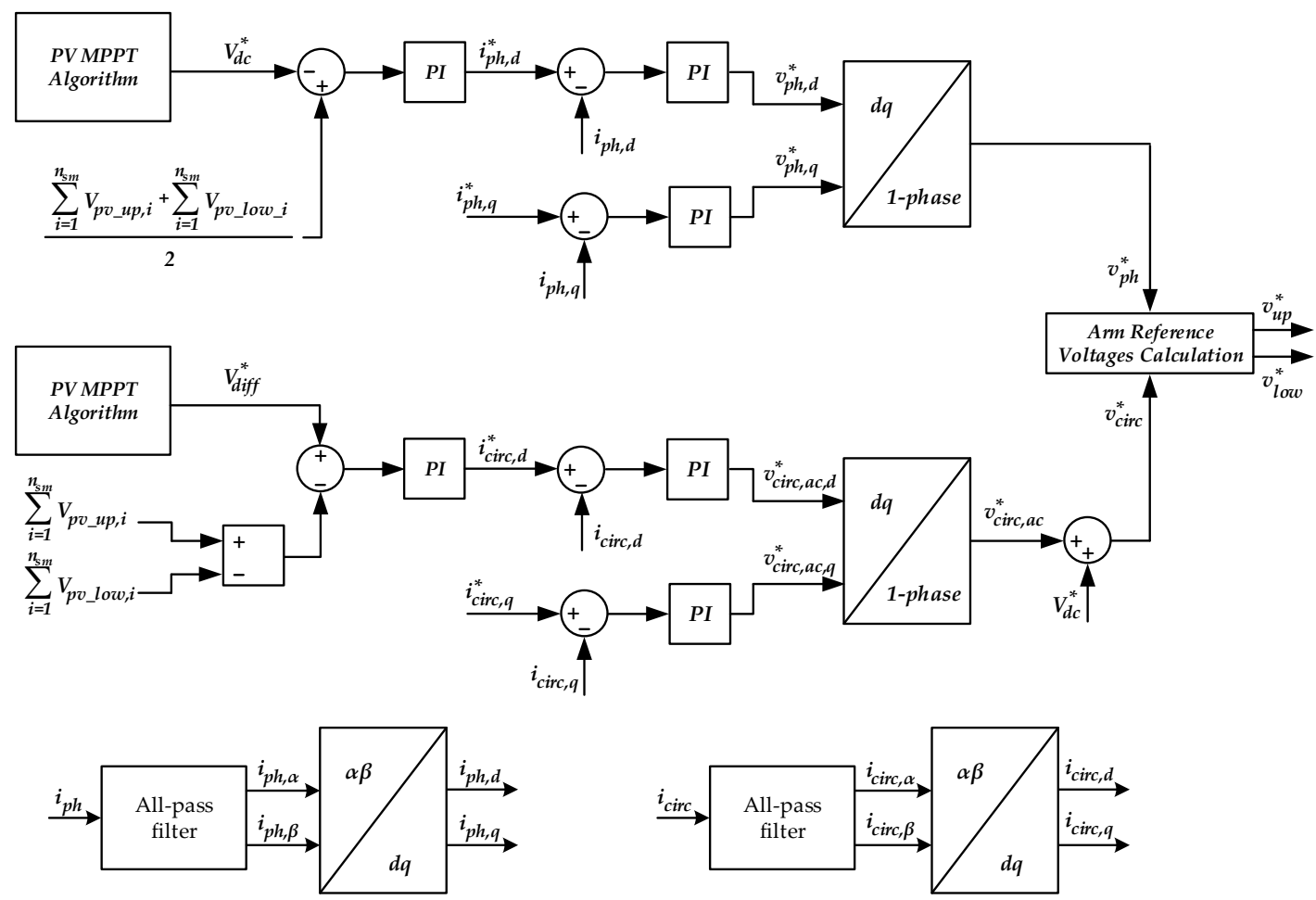

Figure 3. Proposed control structure.

In the proposed control strategy, the MPPT algorithm (Figure 4) is applied to each PV module, and it can be summarized in the following two steps. (i) The currents, $i_{p v \_} u p, i$ and $i_{p v \_l o w, i}$, and voltages, $V_{p v \_u p, i}$ and $V_{p v \_l o w, i}$, of each PV module of the two arms, are measured, and thus, the power produced is obtained; (ii) A positive or negative voltage perturbation is applied until the algorithm reaches the maximum power point, which is when the ratio of $d P / d V$ is ideally equal to 0 . The absolute value of the perturbation, $\delta V$, applied depends on the distance from the real maximum power point according to different thresholds implemented in the controller:

$$
\left[\sigma_{L}\right]<\frac{P_{k}-P_{k-1}}{V_{k}-V_{k-1}}<\left[\sigma_{H}\right] ; P_{k}=V_{k} I_{k}
$$

where $\left[\sigma_{L}\right]$ and $\left[\sigma_{H}\right]$ are vectors composed of $N$ thresholds as follows:

$$
\begin{aligned}
& {\left[\sigma_{L}\right]=\left[\begin{array}{lllll}
0 & \sigma_{1} & \sigma_{2} & \ldots & \sigma_{N-1}
\end{array}\right]} \\
& {\left[\sigma_{H}\right]=\left[\begin{array}{lllll}
\sigma_{1} & \sigma_{2} & \ldots & \sigma_{N-1} & \infty
\end{array}\right] .}
\end{aligned}
$$

$V_{k}, I_{k}$, and $P_{k}$ are, respectively, the voltage, current and power of the PV modules at time instant $k$. The outputs of the MPPT controller are all the optimal voltages of each PV module of the two arms, $V_{p v \_m p p t \_u p, i}$ and $V_{p v \_m p p t \_l o w, i}$.

\subsection{Power Management System}

Because a single-phase system was analyzed, we decided to use one of the orthogonal signal techniques [32,33] and $d q$ transformations, which made it possible to implement the control system in a synchronous reference frame [34]. The orthogonal signal generation techniques needed to create a fictitious imaginary component of the real electric quantity. We chose to use an all-pass filter that could easily approximate the Hilbert transformation [32]. The latter, from a mathematical point of view, can provide a signal that in the Fourier domain has the same harmonic content of the transformed 
signal with all the components shifted by $-90^{\circ}$. The all-pass filter was synthesized by the following Laplace function:

$$
H(s)=\frac{\omega_{f}-s}{\omega_{f}+s}
$$

where $\omega_{f}$ is the fundamental angular frequency, and $s$ is the Laplace variable.

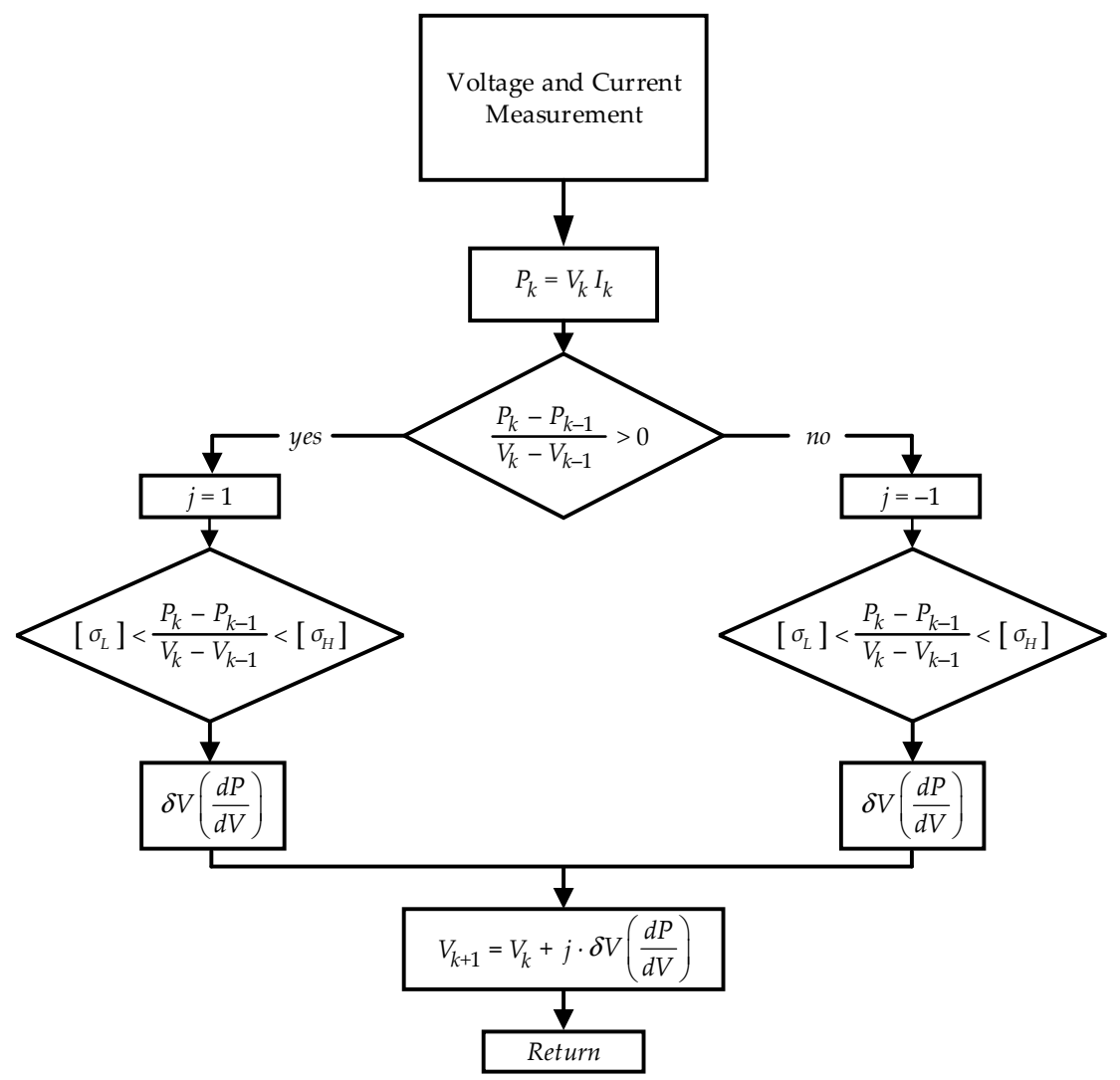

Figure 4. Maximum power point tracking (MPPT) flowchart.

The $\alpha \beta$ coordinates of the system can be obtained using the Hilbert transformation. In particular, the $\beta$ component turned out to lag by $90^{\circ}$ with respect to the fundamental one. Then, the $d q$ transformation from a rotating to stationary frame is given by the following:

$$
\left[\begin{array}{l}
x_{d}(t) \\
x_{q}(t)
\end{array}\right]=\left[\begin{array}{cc}
\cos (\theta) & \sin (\theta) \\
-\sin (\theta) & \cos (\theta)
\end{array}\right]\left[\begin{array}{c}
x_{\alpha}(t) \\
x_{\beta}(t)
\end{array}\right]
$$

where $\theta$ represents the electrical voltage angle.

In order to ensure the maximum power produced by the PV systems, a control system oriented on the grid voltage was used, as shown in Figure 3. This controller generated the output phase voltage and circulating voltage references as functions of the voltage references provided by the MPPT controller.

The power management system could be subdivided into two subsystems: the grid and circulating controllers. Each of these two controllers was composed of two inner PI regulators and one outer PI regulator. 


\subsubsection{Grid Controller}

The outer control loop of the grid controller tracked the dc bus voltage to the reference one. The latter was defined according to the mean value of the MPPT reference voltages as in the following equation:

$$
V_{d c}^{*}=\frac{\sum_{i=1}^{n_{s m}} V_{p v \_m p p t \_u p, i}+\sum_{i=1}^{n_{s m}} V_{p v \_m p p t \_l o w, i}}{2} .
$$

It is worth noting that, unlike the control proposed in [27], in the present work, the dc voltage reference was not fixed and could change as a function of the irradiance. Therefore, from the outer PI regulator, the direct component of the current reference, $i_{p h, d^{\prime}}^{*}$ proportional to the maximum active achievable power, was obtained. Instead, the quadrature component of current reference $i_{p h, q}^{*}$ made it possible to regulate the desired reactive power. For the sake of simplicity, its reference was assumed to be equal to 0 in order to exchange the rated active power at a unitary power factor.

The inner control loop regulated the direct and quadrature components of the grid current and reference voltages $v_{p h, d}^{*}$ and $v_{p h, q}^{*}$ were generated by means of two inner PI controllers. Moreover, the feed-forward terms could be used to improve the dynamic response. The inverse $d q$ transform yielded the output grid voltage reference, $v_{p h}^{*}$, which corresponded to the $\alpha$ component.

\subsubsection{Circulating Controller}

The direct component of the circulating current reference, $i_{\text {circ, },^{*}}^{*}$ similar to that of the grid current reference, was generated through a PI controller that tracked the difference between the upper and lower optimal voltages as follows:

$$
V_{d i f f}^{*}=\sum_{i=1}^{n_{s m}} V_{p v \_m p p t \_u p, i}-\sum_{i=1}^{n_{s m}} V_{p v \_m p p t \_l o w, i} .
$$

This controller was implemented in order to guarantee that each arm could operate at its own optimal average voltage providing its maximum active power. Therefore, the direct component of the circulating current was zero only if the two arms had the same average irradiance. Otherwise, if the two arms had different average irradiances, this circulating current component had to be different from zero to allow a power imbalance between the two arms. The quadrature component of reference circulating current $i_{\text {circ, } q}^{*}$ was set equal to 0 . In this way, the reactive power exchanged by the two arms was proportional to the direct component. In fact, the voltages of the two arms were not in phase with the grid voltage. This was obvious because the active power was exchanged with the grid through an inductive line. This displacement was the load angle. Therefore, even if the reactive power exchanged with the grid was zero (unity power factor), the reactive power needed to charge the inductors was given by the MMC.

The inner control loop regulated the direct and quadrature components of the circulating current and, by means of two inner PI controllers, reference voltages $v_{c i r c, a c, d}^{*}$ and $v_{c i r c, a c, q}^{*}$ were generated. Moreover, the feed-forward terms could be used to improve the dynamic response. The inverse $d q$ transform yielded the output circulating voltage reference, $v_{c i r c, a c}^{*}$, which corresponded to the $\alpha$ component.

Finally, the upper and lower arm voltage references could be calculated according to (9) and (10).

It is worth noting that each sum of (13) and (14) represents the maximum voltage that can be obtained by each arm when all the SMs are activated (maximum arm voltage). According to (9) and (10), in addition to the ac components, each arm has to be able to synthesize half of the dc voltage reference given by (13). In case of equal irradiance conditions between the two arms, the dc voltage reference coincides with the maximum arm voltages. In this way, the ac voltage components can be synthesized using all the SM voltage levels of the arms. Conversely, in case of different irradiance 
conditions between them, the dc voltage reference deviates from the two maximum arm voltages according to (14), thus, the ac voltage components can be synthesized only using a subpart of the SM voltage levels of the arms. Since the irradiance conditions slightly affect the MPPT voltages, taking it into account in the sizing procedure through the correction factor of (6), it is possible to make the MMC work even for significant irradiance differences between the arms.

\subsection{Submodule Sorting}

To follow the maximum power peak point and exploit the power produced by the PV systems, the following balance algorithm was defined:

- If the arm current is positive, it charges the capacitors; the SM with the farthest capacitor voltage from its theoretical optimal voltage and on the left side of the MPP is activated first to produce the desired output voltage.

- If the arm current is negative, it discharges the capacitors; the SM with the farthest capacitor voltage from its theoretical optimal voltage and on the right side of the MPP is activated first to produce the desired output voltage.

Therefore, with the proposed sorting algorithm, each PV input voltage is compared with its own theoretical optimal voltage and, in this way, it can work continuously around its maximum power point.

\section{Results}

The effectiveness and powerfulness of the proposed DMPPT at the module level were demonstrated through simulations performed in Matlab Simulink ${ }^{\circledR}$. As reported in the previous section, the ac circulating current component was controlled to guarantee the management of the power mismatch between the two arms of the MMC. Moreover, the submodule sorting based on the DMPPT made each PV module work at its own maximum power point. A comparison of the proposed DMPPT controller with the CMPPT one was performed. The latter was simply obtained by using the traditional submodule sorting [35] (instead of the one proposed in Section 4.3) and keeping the average voltage arms equal. This meant that (14) was equal to zero. The traditional SM sorting algorithm ordered them based on the increasing/decreasing values of the voltages of the SM capacitors, while the zeroing of (14) allowed the whole system to work at the maximum point of the equivalent PV array. Moreover, two different solar irradiation scenarios were considered for the comparison. The main parameters of the used MMC-PV system are summarized in Table 1.

Table 1. Main MMC-PV system parameters.

\begin{tabular}{ccc}
\hline Parameters & Value & Units \\
\hline Rated plant power $P_{\text {rated }}$ & 6 & $\mathrm{~kW}$ \\
Rated grid voltage $(\mathrm{rms}) v_{g}$ & 230 & $\mathrm{~V}$ \\
Grid resistance $R_{g}$ & 140 & $\mathrm{~m} \Omega$ \\
Grid inductance $L_{g}$ & 3.9 & $\mathrm{mH}$ \\
Arm resistance $R_{\text {arm }}$ & 1 & $\mathrm{~m} \Omega$ \\
Arm inductance $L_{a r m}$ & 1 & $\mathrm{mH}$ \\
Mutual arm inductance $M_{a r m}$ & 0.99 & $\mathrm{mH}$ \\
SM capacitor $C_{s m}$ & 10 & $\mathrm{mF}$ \\
dc bus capacitor $C_{d c}$ & 2 & $\mathrm{mF}$ \\
Correction factor for power regulation $k$ & 1.1 & - \\
Minimum operational dc voltage $v_{d c, \text { min }}$ & 715.6 & $\mathrm{~V}$ \\
Number of SMs per arm $n_{s m}$ & 10 & - \\
\hline
\end{tabular}

Moreover, each PV power module, $P_{p v \_}$, was modeled as follows [36]:

$$
P_{p v_{\_} i}=\left(2.06 \cdot G_{i}-1.58 \times 10^{-8}-1.58 \times 10^{-8} \cdot e^{\left(0.72 \cdot V_{p v_{-} i} / n_{p v_{-} s e r i e s}\right)}\right) \cdot n_{p v_{\_} \text {parallel }} \cdot V_{p v_{-} i}
$$


where $G_{i}$ and $V_{p v_{-} i}$ are the solar irradiation and voltage of the $i$-th PV module, respectively. The parameters of the PV modules are listed in Table 2. For the sake of simplicity, all the simulations were performed considering the $\mathrm{PV}$ temperature fixed at $25^{\circ} \mathrm{C}$. For this reason, the (15) contains the constant parameters calculated for that temperature. This is because a change in the temperature leads to a different maximum power point without changing the shape of the PV characteristic.

Table 2. PV module parameters.

\begin{tabular}{ccc}
\hline Parameters & Value & Units \\
\hline Rated power $P_{p v}$ & 42.53 & $\mathrm{~W}$ \\
Minimum operative irradiance $G_{m i n}$ & 200 & $\mathrm{~W} / \mathrm{m}^{2}$ \\
Minimum optimal operative PV voltage $V_{m p p t, m i n}$ & 19.9 & $\mathrm{~V}$ \\
Number of series PV sub-module $n_{p v \_s e r i e s}$ & 2 & - \\
Number of parallel PV sub-module $n_{p v \_p a r a l l e l}$ & 4 & - \\
\hline
\end{tabular}

\subsection{Scenario 1. Partial Shading Conditions in One Arm}

In this case, a partial shading condition between the two arms was analyzed. Initially, both the arms were irradiated at the maximum value, i.e., $1000 \mathrm{~W} / \mathrm{m}^{2}$. Then, after $7 \mathrm{~s}$, the solar irradiance fell to $300 \mathrm{~W} / \mathrm{m}^{2}$ for all the PV modules embedded in the lower arm (Table 3). The simulation results for the two control strategies are reported in Figures 5-7.

Table 3. Scenario 1. Different partial shading conditions in one arm.

\begin{tabular}{ccccc}
\hline Submodule & \multicolumn{2}{c}{ Upper Arm } & \multicolumn{2}{c}{ Lower Arm } \\
\hline & \multicolumn{4}{c}{$\mathbf{G}\left(\mathbf{W} / \mathbf{m}^{\mathbf{2}} \mathbf{~}\right.$} \\
\hline & $\mathbf{t}=\mathbf{0 - 7} \mathbf{s}$ & $\mathbf{t}=\mathbf{7 - 1 6} \mathbf{s}$ & $\mathbf{t}=\mathbf{0 - 7} \mathbf{s}$ & $\mathbf{t}=\mathbf{7 - 1 6} \mathbf{s}$ \\
\hline SM1 & 1000 & 1000 & 1000 & 300 \\
SM2 & 1000 & 1000 & 1000 & 300 \\
SM3 & 1000 & 1000 & 1000 & 300 \\
SM4 & 1000 & 1000 & 1000 & 300 \\
SM5 & 1000 & 1000 & 1000 & 300 \\
SM6 & 1000 & 1000 & 1000 & 300 \\
SM7 & 1000 & 1000 & 1000 & 300 \\
SM8 & 1000 & 1000 & 1000 & 300 \\
SM9 & 1000 & 1000 & 1000 & 300 \\
SM10 & 1000 & 1000 & 1000 & 300 \\
\hline
\end{tabular}

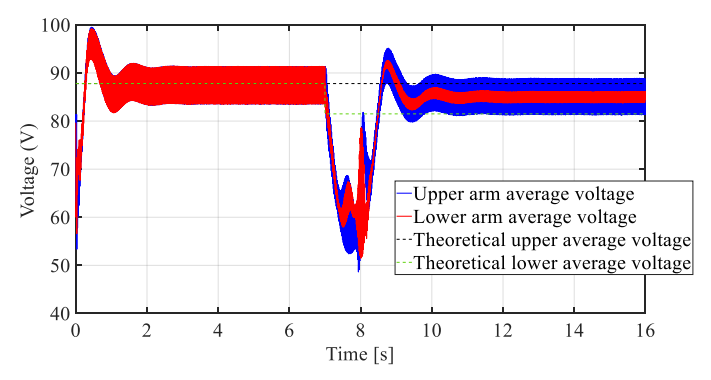

(a)

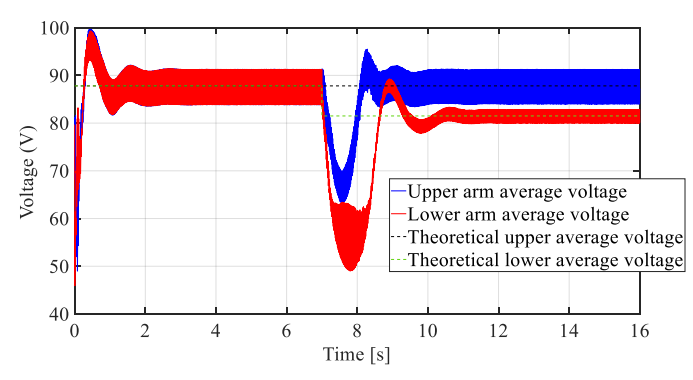

(b)

Figure 5. Average arm voltages: (a) Centralized MPPT (CMPPT) control; (b) Distributed MPPT (DMPPT) control. 


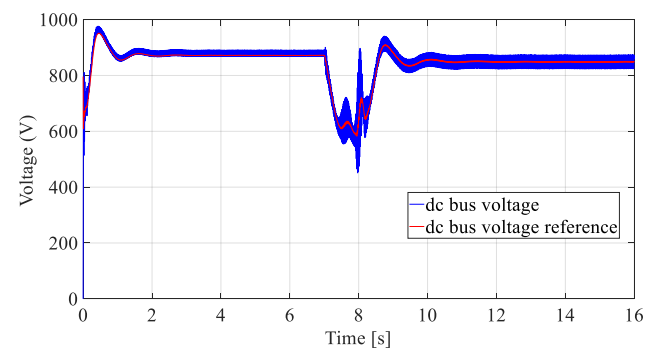

(a)

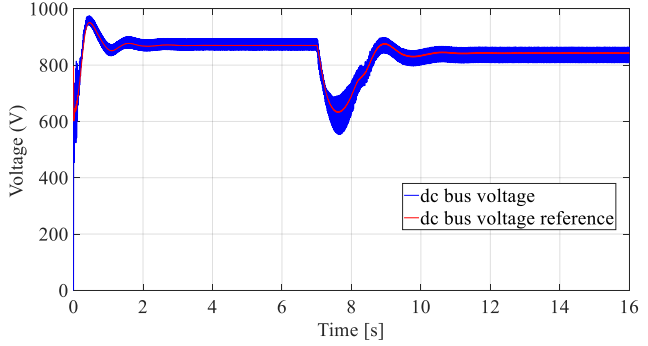

(b)

Figure 6. dc bus voltage: (a) CMPPT control; (b) DMPPT control.

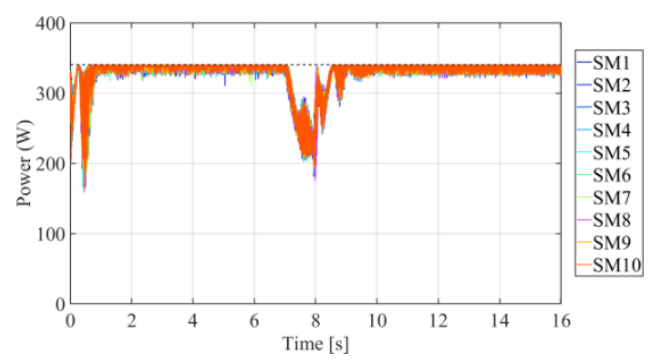

(a)

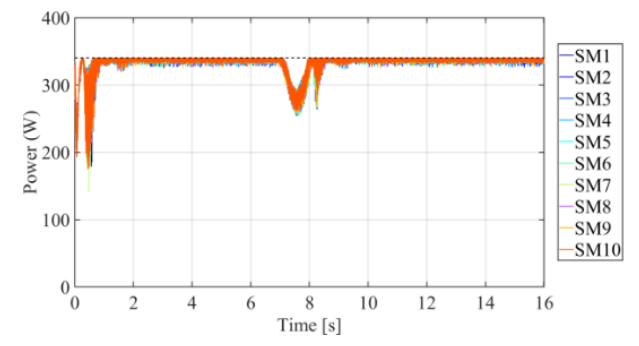

(c)

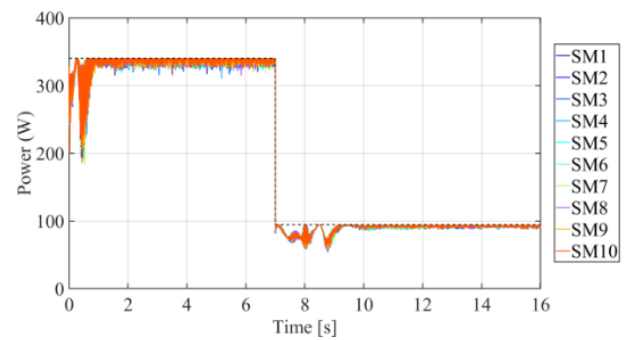

(b)

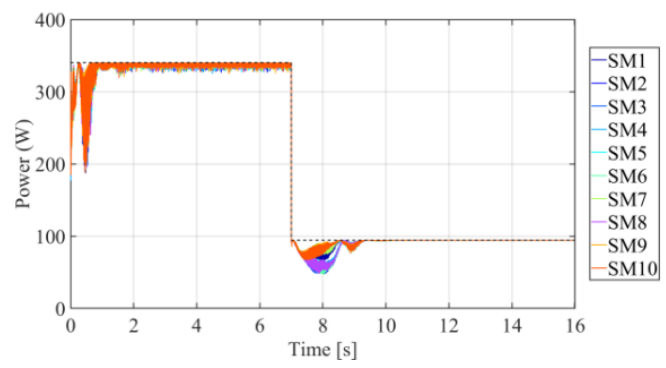

(d)

Figure 7. PV module powers: (a) CMPPT control-upper arm; (b) CMPPT control-lower arm; (c) DMPPT control-upper arm; (d) DMPPT control-lower arm. The dashed lines represent the maximum available power.

Looking at Figure 5, it is possible to recognize the different behaviors of the arm voltages for the two control strategies. In particular, in the time interval of $0-7 \mathrm{~s}$, both of them practically give the same results in terms of both the powers and voltages of the PV modules. This is because the solar irradiation is the same for all the PV modules embedded in the arms. On the other hand, in the time interval of 7-16 s, where the solar irradiation of all the PV modules of the lower arm falls to $300 \mathrm{~W} / \mathrm{m}^{2}$, the behaviors of the two controllers yield different results. In fact, the CMPPT controller forces the two arm voltages (upper and lower) to be equal because the difference between them is controlled to be zero. In the DMPPT controller, the arm voltages are instead free to follow their own theoretical voltages. In both cases, the dc bus voltage changes the steady state value based on the different irradiance conditions, as reported in Figure 6. Figure 7 shows the PV module powers for the two controllers compared with the maximum available powers (indicated as a black dashed line). The latter are related to the power that can be extracted from each PV module if they could work at their maximum power points. From this figure, we can note that the behaviors of the actual PV module powers in the time interval of $0-7 \mathrm{~s}$ are quite similar to each other. On the other hand, in the time interval of 7-16 s, where the power mismatch between the two arms appears, the DMPPT controller presents a better efficiency 
(calculated as the ratio between the sum of all the actual PV module powers and the sum of all the maximum available ones), because each arm can work at the proper theoretical average voltage.

\subsection{Scenario 2. Different Partial Shading Conditions for One and between Arms}

In this scenario, a partial shading condition between the two arms was analyzed. As in the previous scenario, in the time interval of $0-7 \mathrm{~s}$, both arms were irradiated at the maximum value, i.e., $1000 \mathrm{~W} / \mathrm{m}^{2}$. Then, after $7 \mathrm{~s}$, the solar irradiance was changed as reported in Table 4 . The simulation results for the two control strategies are reported in Figures 8-10.

Table 4. Scenario 2. Different partial shading conditions for both arms.

\begin{tabular}{ccccc}
\hline Submodule & \multicolumn{2}{c}{ Upper Arm } & \multicolumn{2}{c}{ Lower Arm } \\
\hline & \multicolumn{4}{c}{$\mathbf{G}\left(\mathbf{W} / \mathbf{m}^{\mathbf{2}} \mathbf{~}\right.$} \\
\hline & $\mathbf{t}=\mathbf{0 - 7} \mathbf{s}$ & $\mathbf{t}=\mathbf{7 - 1 6} \mathbf{s}$ & $\mathbf{t}=\mathbf{0 - 7} \mathbf{s}$ & $\mathbf{t}=\mathbf{7 - 1 6 ~ s}$ \\
\hline SM1 & 1000 & 1000 & 1000 & 250 \\
SM2 & 1000 & 1000 & 1000 & 250 \\
SM3 & 1000 & 250 & 1000 & 250 \\
SM4 & 1000 & 1000 & 1000 & 250 \\
SM5 & 1000 & 1000 & 1000 & 250 \\
SM6 & 1000 & 1000 & 1000 & 1000 \\
SM7 & 1000 & 1000 & 1000 & 250 \\
SM8 & 1000 & 1000 & 1000 & 1000 \\
SM9 & 1000 & 1000 & 1000 & 250 \\
SM10 & 1000 & 1000 & 1000 & 250 \\
\hline
\end{tabular}

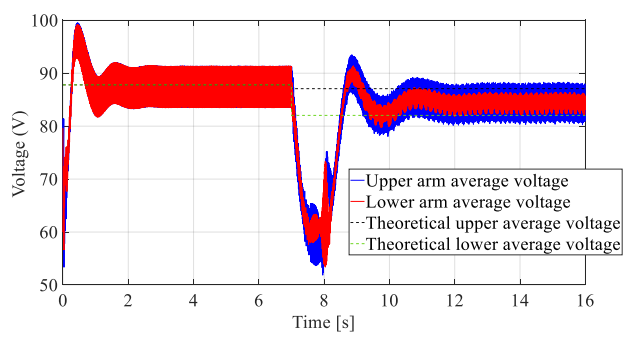

(a)

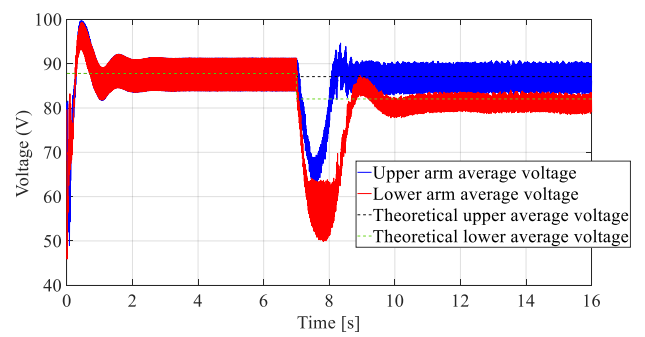

(b)

Figure 8. Average arm voltages: (a) CMPPT control; (b) DMPPT control.

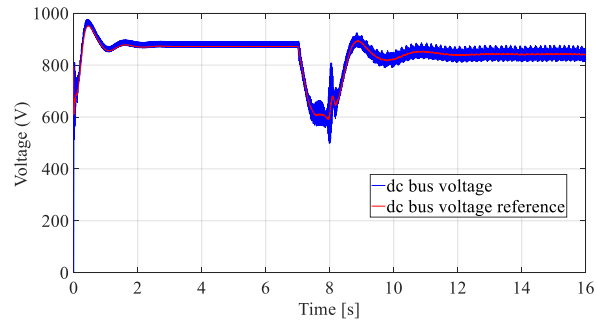

(a)

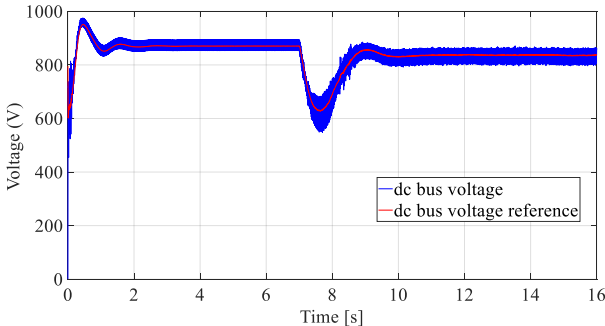

(b)

Figure 9. dc bus voltage: (a) CMPPT control; (b) DMPPT control. 


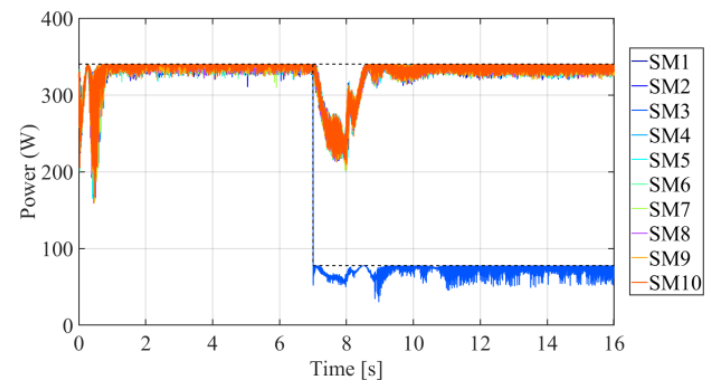

(a)

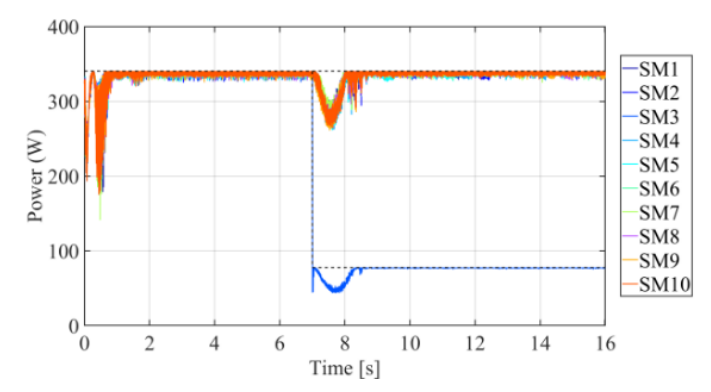

(c)

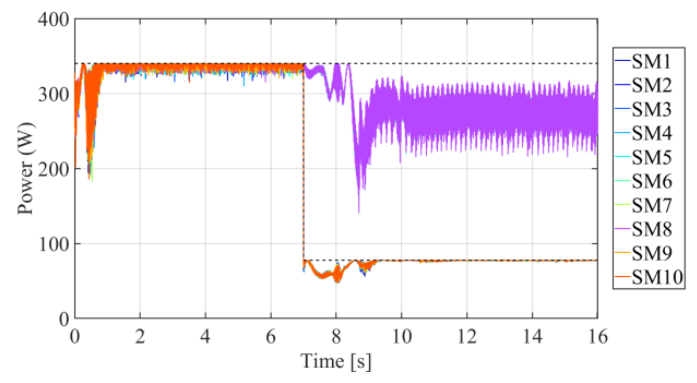

(b)

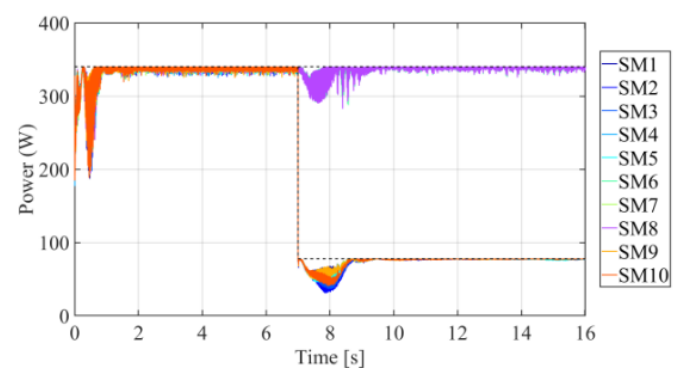

(d)

Figure 10. PV module powers: (a) CMPPT control-upper arm; (b) CMPPT control-lower arm; (c) DMPPT control-upper arm; (d) DMPPT control-lower arm. The dashed lines represent the maximum available power.

Looking at Figure 8, it is possible to recognize the different behaviors of the arm voltages for the two control strategies. In particular, in the time interval of $0-7 \mathrm{~s}$, the controllers give practically the same results in terms of both the powers and voltages, as in the previous scenario. On the other hand, in the time interval of 7-16 s, the solar irradiation changes, causing a power imbalance between the two arms and in the arms themselves. Moreover, in this case, in the CMPPT controller, the two arm voltages are forced to be the same. In contrast, in the DMPPT controller, the arm voltages are free to follow their own theoretical voltages. As in the previous scenario, the dc bus voltage changes the steady state value based on the different irradiance conditions, as reported in Figure 9. Figure 10 shows the PV module powers for both controllers. From this figure, it is worth noting the robustness of the proposed DMPPT controller. Indeed, even under extreme unbalanced irradiance conditions, the DMPPT controller allows the entire system to work to the maximum power available. This is because each PV module can work at its own maximum power point voltage, which gives the maximum power. On the other hand, the CMPPT controller, as in scenario 1, forces the average arm voltages to be equal. At the same time, unlike scenario 1, where the inner solar irradiation for each arm is the same for all the PV modules, in this case, even the inner solar irradiance is different. Therefore, each PV module is influenced by the solar irradiances of the others. In this case, the CMPPT, making all the modules work at the same point, cannot ensure the full exploitation of the available power. This is clearly shown in Figure 11, where it is clear that there is a significant reduction in the MPPT efficiency for the CMPPT under unbalanced conditions. In contrast, the efficiency of the DMPPT is practically constant despite the unbalanced solar irradiation. 


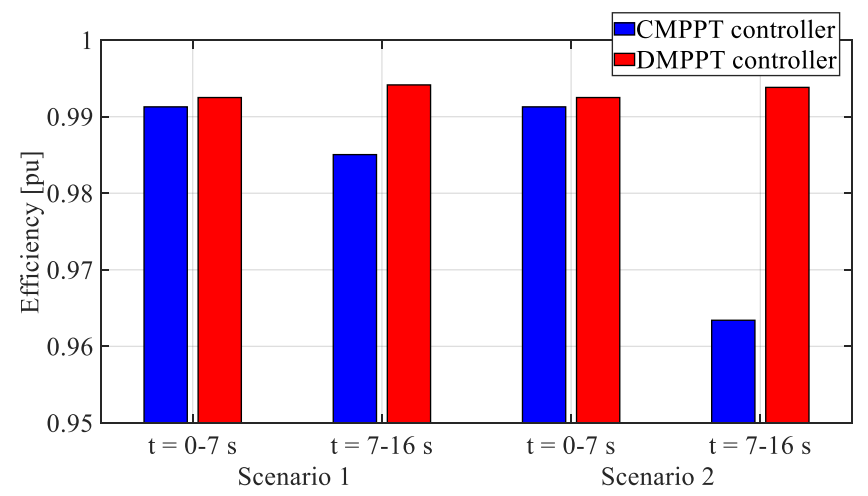

Figure 11. Efficiency of entire system.

\section{Conclusions}

This study modeled a single-phase modular multilevel converter to integrate PV panels in the electrical grid. Moreover, a novel control strategy to obtain the maximum power available under any irradiance conditions was proposed. The proposed control strategy could decouple the control of the grid and circulating currents by changing the dc bus voltage based on the different irradiance conditions. In this way, each arm could work at its theoretical average voltage, allowing the system to show better performances. Moreover, the proposed submodule sorting algorithm compares each SM voltage of the MMC with its theoretical optimal one, which corresponds to the maximum power point voltage of the PV embedded module, allowing each PV module to work around its maximum power point. The validity of the proposed control strategy was demonstrated by comparing it with a conventional CMPPT controller. Different cases of solar irradiance, such as identical irradiance conditions for both arms, a partial shading condition for one arm, and different partial shading conditions for one and between the arms, were simulated. Under the same irradiance condition, both controllers achieve the same efficiency, but under unbalanced irradiance conditions, the DMPPT controller could produce higher output power close to the maximum available.

Author Contributions: Conceptualization, S.B., M.B. and L.P.; methodology, S.B., M.B. and L.P.; software, S.B., and M.B.; validation, S.B., M.B. and L.P.; investigation, S.B. and M.B.; writing-original draft preparation, S.B. and M.B.; writing-review and editing, S.B., M.B. and L.P.; supervision, L.P.; project administration, L.P. All authors have read and agreed to the published version of the manuscript.

Funding: This research received no external funding.

Conflicts of Interest: The authors declare no conflict of interest.

\section{References}

1. Kasper, M.; Bortis, D.; Kolar, J.W. Classification and Comparative Evaluation of PV Panel-Integrated DC-DC Converter Concepts. IEEE Trans. Power Electron. 2014, 29, 2511-2526. [CrossRef]

2. Bowtell, L.; Ahfock, A. Direct current offset controller for transformerless single-phase photovoltaic grid-connected inverters. IET Renew. Power Gener. 2010, 4, 428-437. [CrossRef]

3. Hu, H.; Harb, S.; Kutkut, N.; Batarseh, I.; Shen, Z.J. A review of power decoupling techniques for microinverters with three different decoupling capacitor locations in PV systems. IEEE Trans. Power Electron. 2013, 28, 2711-2726. [CrossRef]

4. Wu, L.; Zhao, Z.; Liu, J. A single-stage three-phase grid-connected photovoltaic system with modified MPPT method and reactive power compensation. IEEE Trans. Energy Convers. 2007, 22, 881-886.

5. Balasubramanian, I.R.; Ganesan, S.I.; Chilakapati, N. Impact of partial shading on the output power of PV systems under partial shading conditions. IET Power Electron. 2014, 7, 657-666. [CrossRef]

6. Chen, K.; Cheng, Y.; Tian, S.; Bai, L. An improved MPPT controller for photovoltaic system under partial shading condition. IEEE Trans. Sustain. Energy 2014, 5, 978-985. [CrossRef] 
7. Bidram, A.; Davoudi, A.; Balog, R.S. Control and circuit techniques to mitigate partial shading effects in photovoltaic arrays. IEEE J. Photovoltics 2012, 2, 532-546. [CrossRef]

8. Bastidas-Rodriguez, J.D.; Franco, E.; Petrone, G.; Ramos-Paja, C.A.; Spagnuolo, G. Maximum power point tracking architectures for photovoltaic systems in mismatching conditions. IET Power Electron. 2014, 7, 1396-1413. [CrossRef]

9. Lyden, S.; Haque, M.E. A simulated annealing global maximum power point tracking approach for PV modules under partial shading conditions. IEEE Trans. Power Electron. 2016, 31, 4171-4181. [CrossRef]

10. Sharma, P.; Agarwal, V. Exact maximum power point tracking of grid-connected partially shaded PV source using current compensation concept. IEEE Trans. Power Electron. 2014, 29, 4684-4692. [CrossRef]

11. Ghasemi, M.A.; Forushani, H.M.; Parniani, M. Partial shading detection and smooth maximum power point tracking of PV arrays under PSC. IEEE Trans. Power Electron. 2016, 31, 6281-6292. [CrossRef]

12. Seyedmahmoudian, M.; Rahmani, R.; Mekhilef, S.; Maung Than Oo, A.; Stojcevski, A.; Soon, T.K.; Ghandhari, A.S. Simulation and hardware implementation of new maximum power point tracking technique for partially shaded PV system using hybrid DEPSO method. IEEE Trans. Sustain. Energy 2015, 6, 850-862. [CrossRef]

13. Sundareswaran, K.; Sankar, P.; Nayak, P.S.R.; Simon, S.P.; Palani, S. Enhanced energy output from a PV system under partial shaded conditions through artificial bee colony. IEEE Trans. Sustain. Energy 2015, 6, 198-209. [CrossRef]

14. Sekhar Sahu, H.; Kumar Nayak, S.; Mishra, S. Maximizing the power generation of a partially shaded PV array. IEEE J. Emerg. Sel. Top. Electron. 2016, 4, 626-637.

15. Ahmad, J.; Ciocia, A.; Spertino, F. A maximum power point tracker of photo voltaic arrays for partial shading conditions. In Proceedings of the International Conference on Industrial Engineering and Operations Management, Dubai, UAE, 3-5 March 2015; pp. 1-5.

16. Keyhani, H.; Toliyat, H.A. Single-stage multistring PV inverter with an isolated high-frequency link and soft-switching operation. IEEE Trans. Power Electron. 2014, 29, 3919-3929. [CrossRef]

17. Casey, L.F.; Prestero, M.G.; Rajda, J. Photovoltaic DC/DC Micro-Converter. U.S. Patent 8,106,537, 31 January 2012.

18. Abdalla, I.; Corda, J.; Zhang, Z. Multilevel DC-link inverter and control algorithm to overcome the PV partial shading. IEEE Trans. Power Electron. 2013, 28, 14-18. [CrossRef]

19. Hu, Y.; Cao, W.; Finney, S.; Xiao, W.; Zhang, F.; McLoone, S.F. New modular structure DC-DC converter without electrolytic capacitors for renewable energy applications. IEEE Trans. Sustain. Energy 2014, 5, 1184-1192. [CrossRef]

20. Hu, Y.; Wu, J.; Cao, W.; Xiao, W.; Li, P.; Finney, S.J.; Li, Y. Ultra-high step-up DC-DC converter for distributed generation by three degrees of freedom (3DoF) approach. IEEE Trans. Power Electron. 2016, 31, 4930-4941. [CrossRef]

21. Walker, G.R.; Sernia, P.C. Cascaded DC-DC converter connection of photovoltaic modules. IEEE Trans. Power Electron. 2004, 19, 1130-1139. [CrossRef]

22. Roman, E.; Alonso, R.; Ibanez, P.; Elorduizapatarietxe, S.; Goitia, D. Intelligent PV module for gridconnected PV systems. IEEE Trans. Ind. Electron. 2006, 53, 1066-1073. [CrossRef]

23. Blumenfeld, A.; Cervera, A.; Peretz, M.M. Enhanced differential power processor for PV systems: Resonant switched-capacitor gyrator converter with local MPPT. IEEE J. Emerg. Sel. Top. Power Electron. 2014, 2, 883-892. [CrossRef]

24. Ramya, G.; Ramaprabha, R. Design methodology of P-Res controllers with harmonic compensation technique for modular multilevel converter fed from partially shaded PV array. In Proceedings of the International Conference on Power Electronics and Drive Systems, Sydney, Australia, 9-12 June 2015; pp. 330-335.

25. Rivera, S.; Wu, B.; Lizana, R.; Kouro, S.; Perez, M.; Rodriguez, J. Modular multilevel converter for large-scale multistring photovoltaic energy conversion system. In Proceedings of the IEEE Energy Conversion Congress and Exposition, Denver, CO, USA, 15-19 September 2013; pp. 1941-1946.

26. Echeverrìa, J.; Kouro, S.; Pérez, M.; Abu-tub, H. Multi-modular cascaded DC-DC converter for HVDC grid connection of large-scale photovoltaic power systems. In Proceedings of the Annual Conference of the IEEE Industrial Electronics Society, Vienna, Austria, 10-13 November 2013; pp. 6999-7005.

27. Rong, F.; Gong, X.; Huang, S.A. Novel Grid-Connected PV System Based on MMC to Get the Maximum Power under Partial Shading Conditions. IEEE Trans. Power Electron. 2017, 32, 4320-4333. [CrossRef] 
28. Lin, L.; He, Z.; Liao, Y.; Li, A.; Hu, J. A pre-charging control scheme for a single-phase modular multilevel converter. In Proceedings of the International Conference on Renewable Power Generation (RPG 2015), Beijing, China, 17-18 October 2015; pp. 1-5.

29. Sotoodeh, P.; Miller, R.D. A single-phase 5-level inverter with FACTS capability using modular multi-level converter (MMC) topology. In Proceedings of the 2013 International Electric Machines \& Drives Conference, Chicago, IL, USA, 12-15 May 2013; pp. 1229-1234.

30. Ouerdani, I.; Bennani, A.; Ben, A.; Slama, B.; Montesinos Miracle, D. Phase Opposition Disposition PWM Strategy and Capacitor Voltage Control for Modular Multilevel Converters. In Proceedings of the International Conference on Recent Advances in Electrical Systems, Hammamet, Tunisia, 20-22 December 2016.

31. Esram, T.; Chapman, P.L. Comparison of photovoltaic array maximum power point tracking techniques. IEEE Trans. Energy Convers. 2007, 22, 439-449. [CrossRef]

32. Monfared, M.; Golestan, S. Control strategies for single-phase grid integration of small-scale renewable energy sources: A review. Renew. Sustain. Energy Rev. 2012, 16, 4982-4993. [CrossRef]

33. Azab, M. Performance of model predictive control approach for single-phase distributed energy grid integration with PQ control. IET Energy Syst. Integr. 2019, 1, 121-132. [CrossRef]

34. Cui, L.; Zhenxing, L.; Li, C.; Jiying, W. A novel control method for single-phase power inverter systems based on Hilbert transform and DQ transform. In Proceedings of the 2017 29th Chinese Control and Decision Conference (CCDC), IEEE, Chongqing, China, 28-30 May 2017; pp. 7430-7435.

35. Qu, L.; Lu, Z.; Liu, C.; He, C. A Sort Method of Balancing Capacitor Voltage of MMC. In Proceedings of the 2019 18th International Symposium on Distributed Computing and Applications for Business Engineering and Science (DCABES), Wuhan, China, 8-10 November 2019; pp. 241-244.

36. Piegari, L.; Rizzo, R. Adaptive perturb and observe algorithm for photovoltaic maximum power point tracking. IET Renew. Power Gener. 2010, 4, 317-328. [CrossRef]

(C) 2020 by the authors. Licensee MDPI, Basel, Switzerland. This article is an open access article distributed under the terms and conditions of the Creative Commons Attribution (CC BY) license (http://creativecommons.org/licenses/by/4.0/). 